\title{
The Path of "Recovery" of Yunfu Stone Art in Rural Art Education
}

\author{
Yang Yiqing ${ }^{1,2 *}$ \\ ${ }^{1}$ Faculty of Design and Architecture, Universiti Putra Malaysia, Selangor Malaysia,47300. \\ ${ }^{2}$ Guangzhou Huali Science and Technology Vocational College, Guangzhou Guangdong,510000. \\ ${ }^{*}$ Corresponding author.Email:gs61942@student.upm.edu.my
}

\begin{abstract}
In recent years, the Yunfu stone industry has advanced towards the route of fine craftsmanship, and the overall level has been greatly improved. With the development of The Times, Yunfu stone art culture is also facing problems such as market development. We through the questionnaire and the social investigation, summarizes the status quo of Yunfu rural art education and the present situation of stone art, the results put forward their own views and countermeasures, its purpose is to explore the cloud pumice art culture in rural local art education in "activation" path, from the aspects of laying solid foundation of traditional culture better to the revitalization of rural, help local culture construction, improve the cultural identity of local residents; it can improve the level of rural art education and the average aesthetic ability of local residents. To further promote the construction of local industries and promote the development of the local economy.
\end{abstract}

Key words: Intangible cultural heritage, Rural art education, Stone art, Recovery

\section{INTRODUCTION}

It is a simple and tough task to revitalize the traditional intangible cultural heritage in rural revitalization. The reason why it is simple is that this intangible cultural heritage is the crystallization of our deep-rooted traditional thoughts and culture. It has been in the minds, blood and hearts of our ancestors and us for a long time, just like the ability we were born with. But why is it hard? As for the intangible cultural heritage that has existed for thousands of years, in today's society, which is subject to the impact of foreign culture, how can we integrate the essence and dross with modern culture, satisfy contemporary aesthetics, apply them in our modern life, and get the recognition of contemporary Chinese people.

\section{CURRENT SITUATION OF RURAL REVITALIZATION IN YUNFU CITY}

Many young people from rural areas prefer to work in big cities like Guangzhou, Beijing, Shanghai and Shenzhen as China's urbanization process intensifies. By the end of 2019, the separated population of Yunfu was 478,451 , among which 377,548 were floating population. Among the floating population, there were 68,221 migrants from other provinces and 309,327 migrants from within the province. It can be seen from the above data that the outflow floating population of Yunfu city is far larger than the inflow population. When the middle-aged and young workers in the villages are leave, only children and the elderly were left, and even the phenomenon of "hollowing out" of the villages appeared. In order to solve this problem, the "Beautiful countryside" construction and "Rural revitalization" strategy are the policies put forward by China in recent years. Since the implementation of the policy has achieved some results, but there are still some problems. In particular, in the process of rural vitalization, there has been a problem of focusing on the "external" rather than the "internal", and many beautiful rural areas are still only superficial. These rural construction lacks cultural support, and the inheritance of local traditional intangible cultural heritage is not in place. Many rural areas do not pay attention to the inheritance and cultivation of local intangible cultural heritage, which directly leads to the loss of local culture, which leads to the lack of identity of local residents to their hometown, the increase in migrant population, the decrease of migrant population, and the backward economic development, falling into a vicious circle[1]. 
Rural revitalization combined with local intangible cultural heritage and rural education is a very good way to solve many of the problems mentioned above. Such as rural revitalization strategy in Yunfu city planning (2018-2022) has mentioned, focus on promoting Ancient Water Town, an ancient village, east guangdong mini-sculpture Yunfu orchid village, Nanjiang industrial park and cultural creative industry base and so on the construction of tourist resources, deepen the historical custom, stone art culture and other cultural and leisure sightseeing agriculture and so on a variety of industrial convergence development. According to the summary table of major projects of the Implementation of rural revitalization Strategy (2018-2022) of Yunfu City, there are 78 major projects of rural revitalization in yunfu city, with a total investment of about 3.15 million yuan. Among them, there are 14 projects involving rural tourism, and 8 are clearly identified as cultural tourism projects. However, most of these projects are related to medicine, horticulture and ecological construction, excluding rural infrastructure projects. Among them, the projects related to the construction of stone art culture or the development of intangible stone art are currently vacant.

\section{THE STATUS QUO OF YUNFU'S LOCAL ART AND CULTURE INHERITANCE AND RURAL ART EDUCATION}

By 2019, the total annual GDP of Yunfu City, where the project is located, is 67.764 billion yuan, which lags behind other cities in Guangdong Province. The Chinese government calls on local governments to lift themselves out of poverty by developing characteristic industries and strengthening education. Research team in Yunfu local students, stone art crafts shops and local stone art managements, director of the crafts are visiting survey, understand the local rural art education present situation, we hope can be in local intangible cultural heritage stone art as the breakthrough point of rural art education, to promote the role of education poverty alleviation, crucial and rural poverty in order to achieve the revitalization of the effective cohesion, narrow differences between urban and rural areas.

In the survey, the most obvious problem is that the publicity of stone art culture is less, rural art education is not valued, and local residents have a weak cultural identity. Before 2018, the Yunfu region paid little attention to the inheritance of traditional intangible cultural heritage. Due to economic problems, most villages in the region pay more attention to whether or how much money they can make. As a result, the inheritance and cultivation of local traditional culture are neglected, and the quality of education is not high, leading to the lack of local culture, the lack of local recognition of local villages, the reduction of migrant population, backward economic development and development difficulties. In this process, the lack of rural education has been increasingly exposed, especially in art education. These problems are mainly reflected in the following aspects.

\subsection{Lack of inheritance of local art and culture;}

\subsubsection{Culture shock brought by western art importation}

Since entering the Internet era, information globalization and foreign cultural input, local residents can access different arts and cultures in various regions of the world through the Internet. When other foreign art and culture appear, there will be a huge contrast and impact on the original traditional art and culture. Local residents will have a novel attitude and curious psychology, and are more willing to understand, learn, try and promote the new foreign culture. It is not a bad thing to accept new things and create new artistic aesthetics, but in this process, the spiritual connotation and artistic temperament of Traditional Chinese art (including folk art) are not well passed on, resulting in the gradual loss of traditional culture and national spirit.

Since the 18th National Congress of the Communist Party of China, with the support of "cultural confidence", many families are still more willing to let the younger generation learn western art, such as drawing, gouache and oil painting, rather than traditional local culture, such as Chinese painting or stone carving.

\subsubsection{Traditional art and culture are ignored and poorly inherited}

Under the impact of western artistic concepts, the Chinese traditional aesthetic system has not been activated, but is facing the crisis of collapse. Only with the help of Chinese characters, national costumes and schema symbols of traditional architecture on behalf of Chinese culture to show national characteristics or mark cultural identity in the international art circle. The essence of "Chinese elements", named in the western way of discourse, is the schematic cultural symbol rather than the connotation of traditional art and the essence of traditional culture. Over time, the essence and connotation of traditional art and culture began to change[2]. 


\subsection{Lack of rural art education resources, lack of education support system, implementation cannot be guaranteed}

3.2.1. Lack of rural art education resources
Neglect of arts education is more common in rural areas than in cities. There have been only 144 papers on rural art education since 2001, of which the main data is concentrated on 2019-2021, as shown in Figure 1.

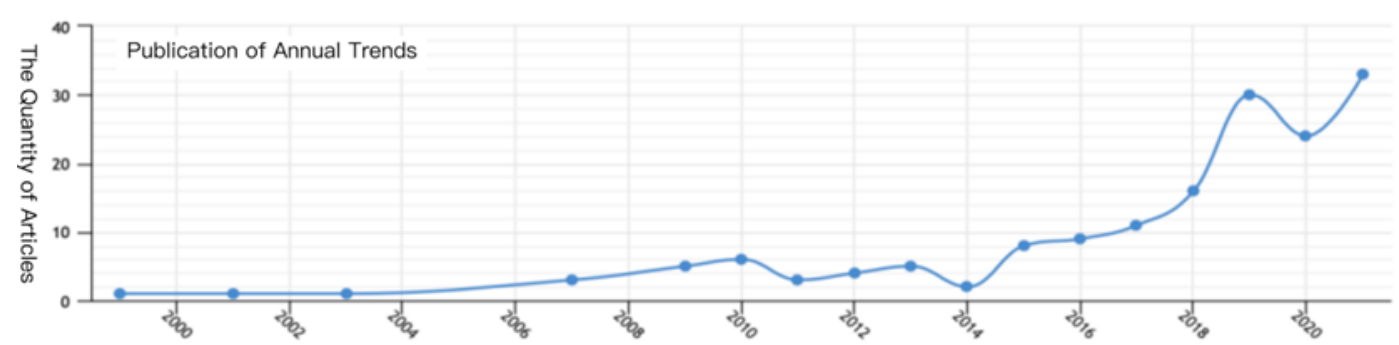

Figure 1 Analysis of the overall trend of literature publication

The remote geographical location of rural schools, backward economy and lack of educational resources make the rural art education fund insufficient, and then it is difficult to implement the teaching hardware, which directly affects the education work of rural art teachers. For example, some rural primary and secondary schools lack teachers and administrators with professional skills and professional qualities in art education, and some rural primary and secondary schools even borrow teachers from other courses as an art teacher. Some schools have only one art teacher and they even have to teach other subjects.

\subsubsection{Lack of education support system}

The rural arts education support system is absent. First of all, as a non-college entrance examination subject, art education is still a "supporting role" in rural education. For example, in some rural primary schools, art classes are still occupied and students do other subjects' homework. Therefore, in addition to supporting school hardware facilities and teachers' resources, it is necessary to improve the status of art education in the minds of teachers and students. Secondly, most rural families are left behind by the elderly or women, and family education is relatively weak, which results in little attention and support for children's artistic accomplishment. Art and cultural activities of primary and secondary school students in rural areas are regarded as "irregular work", which makes it difficult for art education to form a supportive atmosphere for teaching, and the absence of social foundation makes it difficult for rural art education to carry out[3].

To sum up, in the process of rural revitalization, the lack of traditional cultural inheritance affects the lack of local cultural identity of the new generation of young people, which leads to the lack of labor force in the local rural economic development and the lack of art education resource allocation due to the lagging economy. And the local residents' long-term attitude of not paying attention to traditional art and culture further affects the neglect of art education for the new generation.

In view of the above main problems, the author mainly provides solutions from two aspects. On the one hand, the lack of local traditional culture inheritance leads to the weak cultural identity of local young people, the increase of migrant population, the loss of labor force, and the serious "hollowing out" of rural areas. First of all, the "exposure" of stone art products in the lives of local residents can be increased to expand the publicity of stone art culture as shown in Figure 2, to help local residents understand stone art culture, enhance social influence, and enhance local residents' sense of identity with local culture. Because intangible cultural heritage is rooted in people's production and life, full of the vicissitudes of history, reflects the wisdom of the masses, shows a nation's value orientation and aesthetic pursuit, is an essential content in the spiritual and cultural life of rural residents. For example, the genetic bearing one section of the pumice teacher, many of his works with local stone art culture, transfer the breath of Chinese zen aggregates, get the favour of young people from the Chinese traditional aesthetics, reminds people to hometown feelings. Enhancement of local cultural identity, and thus to minimize the loss of young and middle-aged rural labor force and solve the problem of rural hollowing out.

On the other hand, in the investigation, we found that it is worth noting that the original ecological cultural resources and traditional folk art in rural areas are relatively intact and more diversified in form. They have their own characteristics and advantages, but they are indeed the most easily fooled by us. Stone art culture can be integrated into the local country K12 curriculum and local vocational school curriculum teaching art, development with regional and national characteristics of local art curriculum, local materials unique national characteristics and local development of good taste art education, as shown in figure 3 , to improve the status of traditional art in the local art education. For example, 
stone art is a provincial intangible cultural heritage of Guangdong Province, which should be valued, inherited and developed locally. However, there is only one technical school in Yunfu that offers skills courses related to stone art. Although the school has established cooperation with local stone artists to establish master studios, develop curriculum design according to national standards, and establish a "modern apprenticeship".
In short, it is hoped that through the above methods, traditional intangible cultural heritage culture, art education and the construction of "beautiful countryside" can be combined to play a role in rural revitalization of intangible cultural heritage. In addition to improving art education in colleges and primary and secondary schools around Yunfu area, the interaction between teenagers and traditional intangible cultural heritage is enhanced, which plays a positive role in the "recovery" promotion and inheritance of stone art.

\section{CONCLUSION}

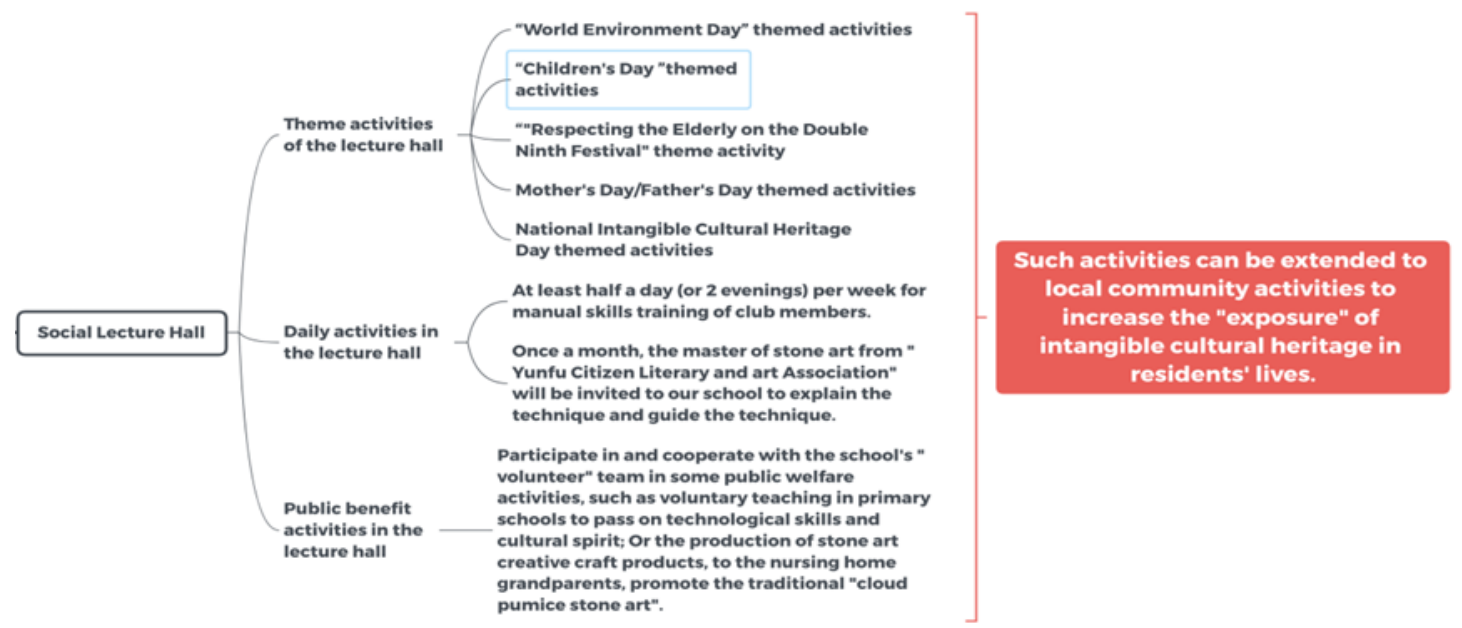

Figure 2 How to Increase the exposure rate of Intangible Cultural Heritage in residents' life

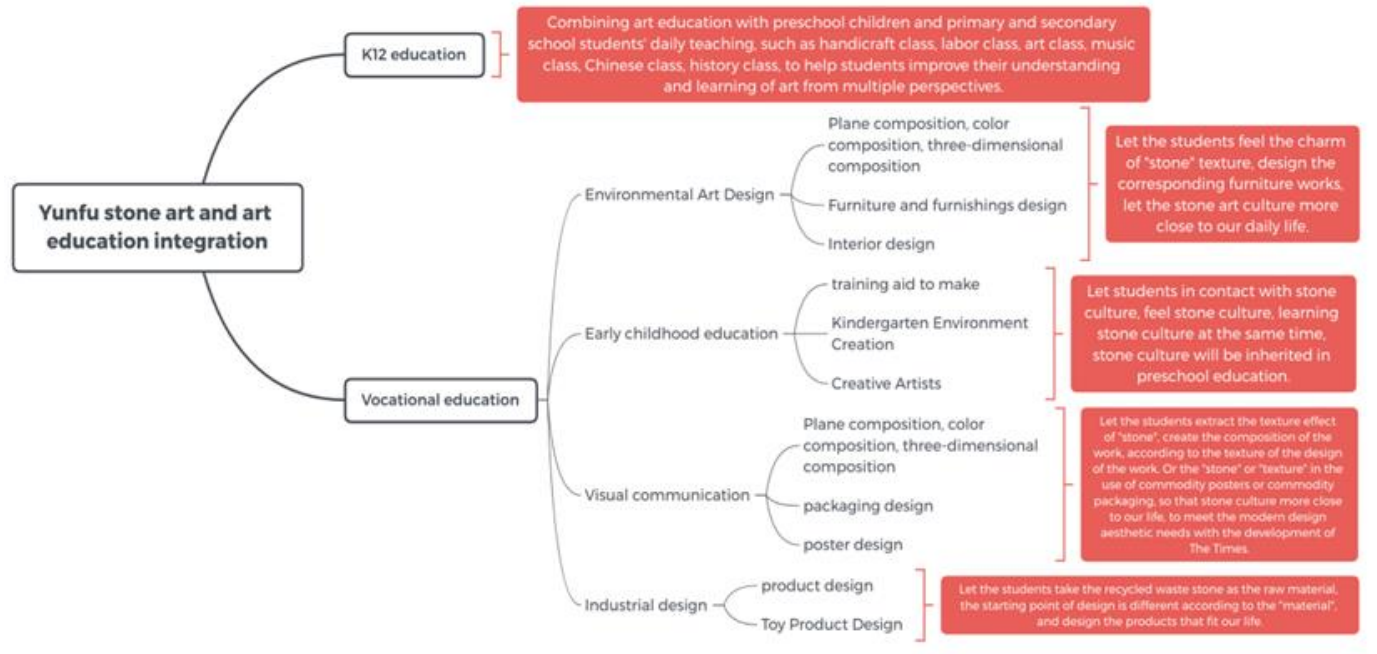

Figure 3 A combination of stone art and rural art education

\section{ACKNOWLEDGMENTS}

This paper is a research on the concept and path of art design service for rural revitalization, taking the activation of Guangdong Intangible Cultural Heritage "Yunfu Stone Art" as an example. The project ID is 2019KZDZX2042. The project source is the Special project in Key fields of Guangdong Universities (social sciences). Special thanks to Lin Xiaoman, Chen Baoqi,
Chen Shufen, Zhao Mingyan, Peng Wanlin and $\mathrm{Hu}$ Hongjing for participating in this project research.

\section{REFERENCES}

[1] Liang Bojun\&Yang Canhong.(2019).The "Yunfu Path" of Guangdong rural revitalization.Origin(12),8-13.doi:CNKI:S UN:YLYT.0.2019-12-004. 
[2]YangYongcong.(2020).Cultural Predominance in Rural Revitalization -- Multiple values of intangible cultural heritage in rural revitalization. Comparative Study on Cultural Innovation(09),44-45.doi:CNKI:SUN:WC BJ.0.2020-09-021.

[3] Wu Keke.(2019).Research on the Inheritance Path of Rural Traditional Culture under the Background of Rural Revitalization Strategy (Master's Thesis, Jiangnan University).https://kns.cnki.net/KCMS/deta il/detail.aspx dbname $=$ CMFD202001\&file name $=1020007457 . \mathrm{nh}$

[4]Rui Xueting, Wu Zhangming \& Zhang Zhicheng.(2021). The significance of art practice to talent cultivation in colleges and universities under the background of rural cultural revitalization. Neijiang Science and Technology (06),96-97. doi:CNKI:SUN:KJNJ.0.2021-06-051.

[5] Gao Wenjing \& Yan Fengyu.(2021). Analysis of difficulties in the development of fine arts education in rural primary schools and its improvement strategies. Research on Fine Arts Education (15),156-157. doi:CNKI:SUN: MSjy.0.2021-15-076.

[6] Jing Yingchun.(2021). Research on the status quo and Countermeasures of art education in primary and secondary schools in western Rural Areas. New Course (11),105. doi:CNKI:SUN: Xkja.0.2021-11-090.

[7] Wang Chao, Guo Zhen \& Shao Yuhan.(2021). Problems and countermeasures of art education in rural schools from the perspective of rural revitalization. Popular Literature and Art (04),180-181. doi:CNKI:SUN: Dzlu.0.2021-04-090.

[8] Duan Peng.(2018). Rural art education in Action. Chinese Primary and Secondary School Fine Arts (10),8-10. doi:CNKI:SUN:ZXMS.0.2018-10-003. 